\title{
Pharmacological treatment of chronic non-malignant pain among elderly persons: an integrative review
}

Salomão Antônio Olivência' Luiza Gabriela Mendes Barbosa ${ }^{1}$ Marcela Rodrigues da Cunha' Ledismar José da Silva'

\section{Abstract}

Objective: The objective of the present study was to perform an integrative review of proposed pharmacological treatments for chronic non-malignant pain in elderly patients. Method: An integrative review was carried out. The search of literature included papers about the treatment of chronic pain among the elderly, published from 2007 to 2017 and available in Portuguese or English. Searches were conducted on the LILACS and MEDLINE electronic databases using the key words "chronic pain", "treatment" and "elderly" combined with the Boolean operator "AND". To analyse methodological quality, the adapted Critical Appraisal Skill Program (CASP) was used. Results: Of a total of 303 studies found, 32 were included. The articles selected included 20 reviews, five observational studies, five clinical trials, one case series and one retrospective study. A total of $75 \%$ of the articles were published in the last five years, of which one was in Portuguese and 31 in English. Conclusion: The results demonstrate a variety of treatments for chronic pain among the elderly population, highlighting the role of opioids which, according to more recent evidence, can be carefully used in treatment. Several drugs, however, have not been specifically tested for the elderly population. A number of factors are relevant in pain management of elderly patients, including comorbidities, polypharmacy and patient functionality. An individualized approach should be applied to elderly patients to improve outcomes and reduce side effects.

Pontifícia Universidade Católica de Goiás, Escola de Ciências Médicas, Farmacêuticas e Biomédicas, curso de Medicina. Goiânia, Goiás, Brasil.

Keywords: Chronic Pain. Drug Terapy. Drug Utilization. Health of the Elderly. 


\section{INTRODUCTION}

Population aging is accompanied by an increase in the incidence of chronic and degenerative diseases, which contribute to the onset of functional pains and limitations ${ }^{1}$. Chronic pain is a prevalent condition in the elderly and has major repercussions on health status, quality of life and biopsychosocial care for this population ${ }^{2-4}$. Studies have shown that pain is one of the most common complaints of the elderly in outpatient medical consultations and that $25 \%$ to $50 \%$ of such individuals in general suffer from chronic pain, with these numbers reaching $80 \%$ in institutionalized elderly persons ${ }^{5,6}$.

According to the International Association for the Study of Pain (IASP), pain is an unpleasant sensation or emotional experience associated with actual or potential tissue damage, and may be acute (lasting less than 12 weeks) or chronic (lasting longer than 12 weeks), as well as presenting several pathophysiological mechanisms ${ }^{7}$. Its consequences are multidimensional, altering the physiological, psychological, functional and social variables of the individual ${ }^{8}$.

The treatment of chronic pain is based on the World Health Organization (WHO) Analgesic Ladder, originally proposed for the treatment of cancer pain. Treatment of low-intensity pain typically involves administration of a non-opioid analgesic and a non-steroidal anti-inflammatory (first step). For pain of moderate intensity, an analgesic associated with a weak opioid (second step) is recommended. For patients with severe pain (third step), strong opioids such as morphine and oxycodone are indicated. In parallel with the drug classes mentioned above, the $\mathrm{WHO}$ also recommends adjuvant drugs such as antidepressants and anticonvulsants, which can be associated with any step or used alone to better manage pain ${ }^{9,10}$.

Physiological and pharmacodynamic changes in senility, comorbidities, cognitive aspects and degree of independence may interfere with the behavior of pain and its management. Elderly people tend to be more susceptible to the effects of medication and also to their adverse effects. Thus, one should be aware of possible unexpected responses to certain medications when beginning pain management in the elderly, which sometimes involves strong drugs such as opioids ${ }^{11}$. The Brazilian and American consensuses of potentially inappropriate drugs for the elderly report that adverse effects in the elderly are at least twice as frequent as in young patients ${ }^{12,13}$. Associated with these factors is polypharmacy, one of the most worrisome aspects of drug therapies in the elderly?.

The objective of this study was to perform an integrative review addressing the drug treatment of chronic non-oncologic pain in the elderly. The study aimed to explore the use of different classes of drugs used in the treatment of pain, as well as their recommendations and specific advantages and disadvantagesfor this population.

\section{METHODS}

An integrative literature review was adopted as a research methodology, since it allowed the use and critical evaluation of scientific evidence of several methodological designs. The preparation of this review was based on six stages, in order to guarantee greater methodological rigor ${ }^{14}$.

First stage: Establishing of the research question, based on the theme, which in this case was, what are the options for the drug treatment of non-oncologic pain in the elderly?

Second stage: a literature search was conducted between October 2016 and June 2017. The databases used were: Latin American and Caribbean Health Sciences Literature (LILACS) and the Medical Literature Analysis and Retrieval System Online (MEDLINE). The descriptors used were: "dor crônica", "tratamento" and "idoso" in Portuguese and "chronicpain", "treatment" and "elderly" in English, all included in the Health Sciences Descriptors (DeCS) and Medical Subject Headings (MeSH). The Boolean operator AND was employed.

The criteria for selecting the articles were: a) articles on the proposed theme, namely chronic non-oncologic pain treatment in the elderly, with individuals older than 60 years considered elderly; b) articles published between 2007 and 2017; c) articles in English or Portuguese; (d) articles available in full; e) articles that met the criteria proposed by the Critical Appraisal Skills Program (CASP) Checklist for Qualitative Research. The 
exclusion criteria were: a) articles that addressed the non-pharmacological treatment of pain; b) articles repeated among the databases.

Third Stage: Categorization of the studies, including the gathering of information such as: identification of the original article and authors, periodical, year of publication, database, methodological characteristics, level of evidence, interventions measured and results found.

Fourth Stage: evaluation of the studies included in the integrative review. The critical analysis of the data was performed following the organization of the selected articles. The CASP instrument was applied with the purpose of guaranteeing the methodological rigor, relevance and credibility necessary for an integrative review of studies with different approaches.

Fifth Stage: Interpretation of results. The discussion of the main results found in literature on the drug treatment of chronic pain in the elderly, the drug classes and their effects on this population was carried out.

Sixth Stage: Writing of review. The results and discussion were presented in a descriptive manner.

\section{RESULTS}

The search identified 303 articles, of which 204 were published between 2007 and 2017. The initial evaluation was performed by reading the title, excluding articles outside the theme of "pain in the elderly". The abstracts of the included articles were evaluated in accordance with the eligibility criteria. The abstracts were evaluated by three independent reviewers and the publications that met the inclusion criteria were evaluated in their entirety.

The final sample for inclusion in the integrative review was 32 articles, of which $75 \%$ were published in the last five years (Figure 1).

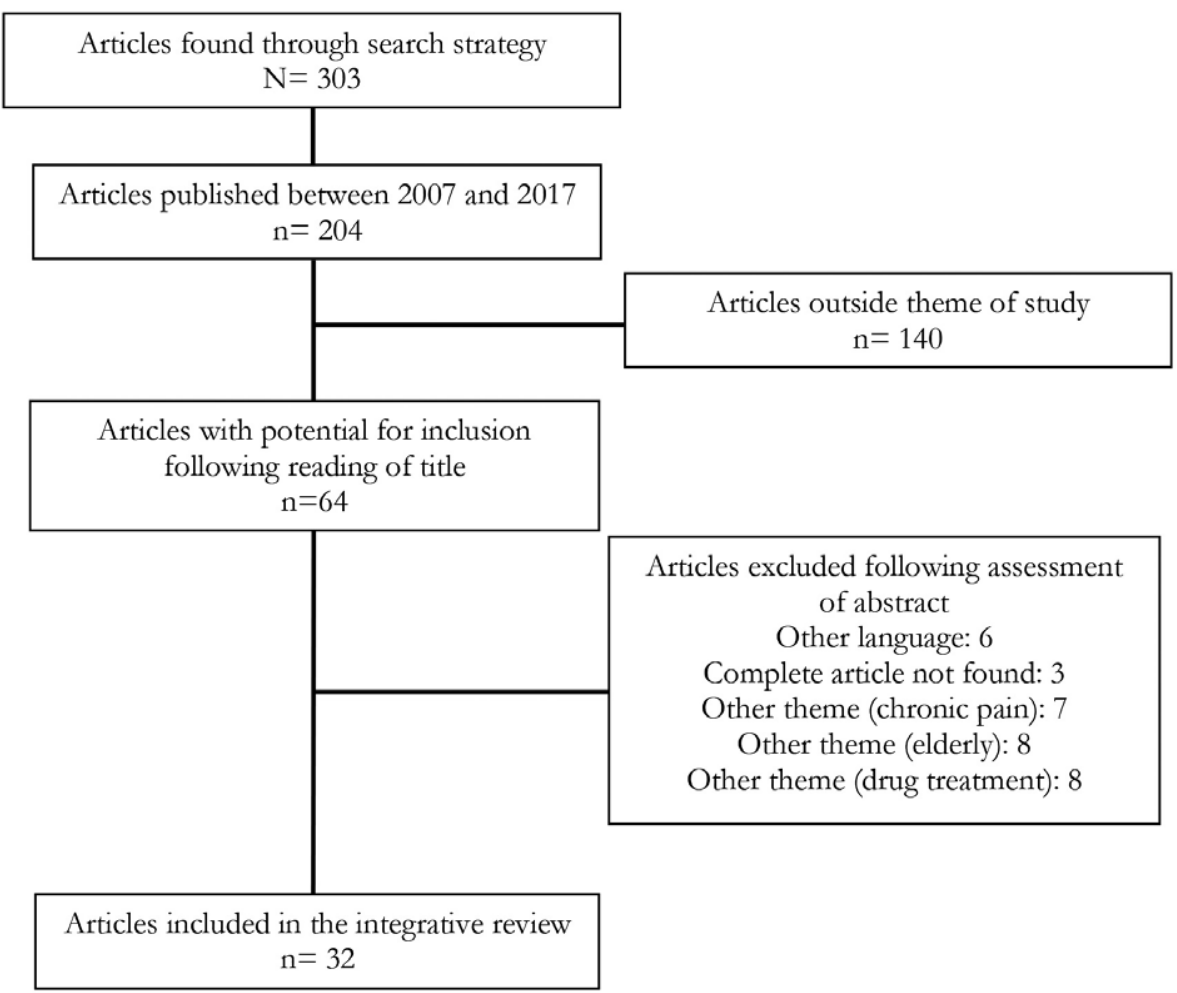

Figure 1. Flowchart of study selection. 


\section{DISCUSSION}

\section{Non-opioid analgesics}

This group of various drugs reduces or interrupts the nerve transmission pathways, reducing nociception, with the main examples being acetaminophen and dipyrone ${ }^{11}$. No studies on the use of dipyrone in chronic pain were found, however, and so this drug was not addressed in the present study.

\section{Acetaminophen}

Popularly known as paracetamol, this drug has analgesic and antipyretic properties. It acts by inhibiting the arachidonic acid cascade. It is the most widely used analgesic, and is the drug of choice for the treatment of mild to moderate pain ${ }^{15}$. Its use in combination with tramadol produces a good response in patients who show no improvement with nonsteroidal anti-inflammatory drugs (NSAIDs) ${ }^{16}$.

It rarely presents side effects and results in few drug interactions. The greatest concern regarding its use is due to its high hepatotoxic potential. In many countries, the drug is considered the leading cause of acute liver failure and it may cause subclinical toxicity even at normal dosages. In alcoholics, there is an increased risk of toxicity, since the hepatic metabolism becomes synergistic ${ }^{17,18}$.

Despite being considered a safe drug for the elderly, there are no studies that specifically address the safety of acetaminophen in this group. According to the Food and Drug Administration (FDA), there is no evidence that doses above $325 \mathrm{mg}$ produce better results, with dosages of up to 2 grams/day recommended for the treatment of chronic pain ${ }^{18,19}$. The use of paracetamol in the elderly should be recommended on an individual basis. Because it is a low-cost and easily accessible drug, it is important to advise the patient about the risks of the indiscriminate use of the drug ${ }^{19,20}$.

\section{Anti-inflammatory drugs}

NSAIDs, along with analgesics, are indicated for the treatment of acute and chronic mild pain, and represent the first step of the WHO analgesic ladder ${ }^{10}$.
NSAIDs possess an antipyretic, analgesic and antiinflammatory action by inhibiting the synthesis of prostaglandins and thromboxanes ${ }^{19}$.Despite the role of NSAIDs as drugs of choice in the treatment of mild to moderate chronic pain, they are potentially inappropriate for the elderly and their indiscriminate and long term use is related to various morbidities and delirium ${ }^{11,12,21-23}$. It is recommended that they are used only when essential and with monitoring ${ }^{21-23}$.

Although diclofenac sodium is a high-potency drug and the most prescribed medication worldwide, it has a high incidence of side effects. The drug is available in oral, topical and adhesive forms, with the last the safest in terms of systemic adverse effects, although it is not as efficient as the oral form ${ }^{24}$. When comparing ibuprofen, diclofenac and celecoxib, the Celecoxib Long-term Arthritis Safety Study (CLASS) found similar results for the risk of cardiovascular disease associated with the use of NSAIDs ${ }^{19}$.

Studies have suggested that selective NSAIDs have greater gastrointestinal effects than nonselective drugs ${ }^{20}$. While celecoxib has a better gastric tolerance profile than ibuprofen and diclofenac, its use for more than six months results in a similar incidence of gastrointestinal effects ${ }^{19}$.It is important to remember that the coadministration of acetylsalicylic acid, which is quite common in the elderly, also reduces the advantage of selective NSAIDs over non-selective NSAIDs, and both cases involve a predisposition to gastric ulcers and reduced safety. Since none of the NSAIDs is completely safe in terms of gastrointestinal effects, the concomitant use of proton pump inhibitors is recommended ${ }^{22}$.

The continuous use of anti-inflammatories can cause renal damage. Cardiorenal effects are usually attributed to traditional drugs such as diclofenac, nimesulide and naproxen. However, a clinical trial by Schwartz et al. (apud Kean et al. $)^{19}$ found that after 28 days of use of selective COX-2 inhibitors (rofecoxib and celecoxib), the changes in renal function were similar to naproxen, resulting in creatinine clearance, weight change, urinary excretion and systolic and diastolic blood pressure ${ }^{19}$.

The choice of NSAID for the treatment of chronic pain states is largely empirical ${ }^{21}$. Some authors suggest a therapeutic trial of one to two weeks, with the treatment maintained if there is a 
satisfactory response. It should be initiated at low doses to determine patient tolerance, with subsequent dose adjustment to maximize efficacy or minimize adverse effects ${ }^{25,26}$.

Opioids

Opioids are a group of compounds that act by binding themselves to the opioid receptors distributed in the nervous system and peripheral tissues, and can act as agonists or antagonists. Fentanyl, hydromorphone, methadone, morphine and oxycodone are agonist opioids, while buprenorphine is partially agonist/antagonist ${ }^{27}$.

They are potent for the control of moderate to severe chronic pain which is refractory to treatment with non-opioid analgesics and anti-inflammatory drugs. ${ }^{18,28}$ Due to the high index of dependence, side effects and lack of knowledge on the part of clinicians, however, there is a fear of prescribing opioids $^{23}$. However, studies have suggested that, when properly recommended for carefully selected elderly, they may offer less risk than NSAIDs ${ }^{27,29,30}$.

Opioid tolerability is an extremely important factor in the treatment of the elderly with chronic pain, since adverse events such as dizziness and sedation are related to an increase in the incidence of falls and, consequently, risk of fractures ${ }^{22,31}$. The main side effects of opioids, however, are gastrointestinal, including constipation, nausea and vomiting ${ }^{9}$. These effects may be amplified by normal physiological changes in the elderly, such as increased gastric $\mathrm{pH}$ and reduced gastric and intestinal motility ${ }^{17,32}$.

\section{Tramadol}

This is a weak opioid and an agonist of the $\mu$-opioid receptor, acting to inhibit the reuptake of monoamines at the central level. Its most common side effects are nausea and vomiting, the reduction of the convulsive threshold withdoses greater than $300 \mathrm{mg} / \mathrm{day}$, and an increased risk of suicide and serotonergic syndrome. Tramadol should therefore be avoided in patients with suicidal ideation or the use of serotonin reuptake inhibitors ${ }^{28,33,34}$. There are few studies for the elderly population and some authors recommend beginning with a dose of 25 to $50 \mathrm{mg}$ day, with a progressive increase of up to $100 \mathrm{mg} /$ day $^{24,28}$.

An observational study by Imamura ${ }^{21}$ evaluated the effects of the combination of tramadol and acetaminophen in patients with chronic low back pain which had not improved with the use of NSAIDs. While the results showed significant improvement of pain after one month of treatment, more interventional studies are necessary to evaluate the long-term results.According to Hirst et al. ${ }^{16}$, tramadol increases the risk of falls and fractures when compared to buprenorphine. Based on data from the British National Health Service, the authors concluded that, even though the drug itself is cheaper, the indirect final costs of falls and fractures are greater than with the use of buprenorphine.

\section{Codine}

This is a weak opioid widely used in the treatment of moderate pain (second step). Twelve times less potent than morphine, it is widely used in combination with other analgesics such as paracetamol. Even though it is a weak opioid, it can cause side effects similar to other such drugs, mainly nausea, vomiting and constipation. No studies were found that evaluated the use of codeine in the elderly population. Evidence in the general population suggests that the drug is related to neurotoxicity in patients with renal impairment, so the American Society of Interventional Pain Physicians (ASIPP) contraindicates its use in patients with creatinine clearance less than $30 \mathrm{~mL} / \mathrm{min} / 1.73 \mathrm{~m}^{2,18,24}$.

\section{Hydrocodone}

Hydrocodone, also known as dihydrocodone, is a semisynthetic opioid synthesized from codeine. It is one of the principal and most used opioids in the treatment of chronic pain in the USA. Even though it is a widely used drug, the ASIPP ${ }^{18}$ states that the evidence of its effects and safety is variable and insufficient. In the search for data in this review only one study on hydrocodone was selected, confirming the need for further studies ${ }^{19}$. 
The study by Broglio et al. ${ }^{35}$ evaluated the efficacy and safety of long-release hydrocodone in the elderly with chronic pain. Patients older than 75 years, with moderate to severe pain, were admitted to treatment for a period of 52 weeks. The results showed that $94 \%$ of patients were satisfied with treatment and reduced pain based on the evaluation index "pain in the last 24 hours". The median dose of the drug in the study ranged from 37.7 to $49.7 \mathrm{mg}$, consistent with ASIPP recommendations, which are 30 to 40 $\mathrm{mg}$ per day. Like other opioids, the main side effects were constipation and nausea, with no incidence of falls ${ }^{18,35}$.

A particular feature of the study was the use of long-release hydrocodone, considered a positive factor by the study subjects. It presents limitations however, such as its post-hoc nature, small population, and the absence of a cognition test in sample selection ${ }^{35}$. In addition, the drug is expensive in Brazil.

\section{Methadone}

Methadone is a popular synthetic opioid with a potent analgesic effect and also several adverse effects. Its pharmacological and pharmacokinetic properties differ from other opioids, producing significant interindividual differences and greater chances of interactions ${ }^{28}$. In addition, it may be related to a prolonged QT interval and the increased risk of Torsades de Pointes when used in high doses ${ }^{36}$.

Case reports by Vu Bach et al. ${ }^{36}$ found a satisfactory response in the improvement of pain with the use of methadone in low doses, ranging from 2.5 to 20 $\mathrm{mg}$, as an adjuvant drug. In this study, the authors concluded that methadone was safe, well-tolerated and effective in controlling pain when offered as a complement to hydromorphone.

According to the ASIPP ${ }^{18}$ consensus for the treatment of pain, methadone is recommended only in the case of the failure of other opioid drugs, with treatment beginning with a dose of two to five $\mathrm{mg} /$ day and a maintenance dose of between 10 and 30 $\mathrm{mg}$ /day. Electrocardiograms prior to and during treatment have been recommended, although there is a limited level of evidence for such recommendations, as most studies involving the drug are case reports, requiring new evidence of greater significance ${ }^{18}$.

\section{Oxycodone}

Oxycodone is a semisynthetic opioid of morphine, derived from thebaine. It is a pure agonist that has a high affinity for $\mu$-opioid receptors and a potency twice as great as morphine ${ }^{30}$. Its use is usually only indicated in cases of severe pain, corresponding to the third step of the analgesic ladder ${ }^{18}$. New studies have shown promising results regarding the use of oxycodone as the first option in the treatment of chronic pain in the elderly ${ }^{37,38}$. The British consensus for the treatment of chronic pain recognizes the prescription of strong opioids in low doses without the previous use of weak opioids when pain is not adequately controlled with analgesics or NSAIDs ${ }^{22}$.

In order to reduce gastrointestinal effects, a prolonged release formulation combining oxycodone and naloxone has been developed and has produced good results for efficacy and safety. Naloxone is an opioid antagonist drug with low systemic bioavailability that predominantly antagonizes opioid receptors in the gastrointestinal tract, preventing the gastric side effects of oxycodone ${ }^{38,39}$.

The oxycodone-naloxone prolonged-release combination has shown analgesic efficacy in studies, with a significant reduction in the incidence of opioid-induced constipation and improvement in patient quality of life $\mathrm{e}^{37,39,40}$. A study conducted by Guerriero et al. ${ }^{37}$ demonstrated statistically significant clinical improvements during oxycodone-naloxone treatment. A total of 60 patients, with a mean age of 81.7 years, received an average dose of 17.4/7.7 $\mathrm{mg}$ daily for four weeks. There was significant improvement in the pain index as well as Barthel's functional scale at the end of four weeks, and the results were maintained after 52 weeks.

According to Malec and Shega ${ }^{24}$, oxycodone has a better safety profile in patients with cardiovascular diseases and reduced renal function than codeine and morphine. It should still be used carefully and with monitoring for possible toxicity, however, since the drug has several metabolites that can accumulate in renal failure. 
Buprenorphine

Buprenorphine has been used in medicine as a treatment for opioid dependence for decades, and studies have demonstrated the analgesic effect of the transdermal presentation of the drug in recent years ${ }^{41,42}$. It is a derivative of thebaine and 25 to 40 times more potent than morphine. It is suggested that its mechanism of action operates through partial agonist effects on the $\mu$ and Kappa opioid receptors, as well as via antagonistic action on the delta receptors ${ }^{15,41,43}$. Initially, it was believed that the partial agonist effect of buprenorphine limited its analgesic effect, but studies have shown that the ceiling effect only exists with respect to respiratory depression, and not analgesia ${ }^{44}$.

Buprenorphine comes in intravenous, sublingual and transdermal forms, with the last the only type available in Brazil and the most currently studied. Adhesives are available in five, 10 and $20 \mathrm{mcg} / \mathrm{h}$ forms, with seven day release. Unlike other drugs, buprenorphine has no systemic accumulation, with mainly intestinal elimination, and is considered safe for patients with renal insufficiency. Its transdermal route of administration prevents firstpass metabolism, contributing to lower rates of drug interactions and adverse effects such as respiratory depression and immunosuppression ${ }^{29,42,45}$.

A study by Überall and Müller-Schwefe ${ }^{45}$ evaluated the efficacy of buprenorphine in the treatment of chronic pain in the elderly. A total of 891 individuals, with a mean age of 72.8 years, received doses between 5 and $30 \mathrm{mg} / \mathrm{h}$ during the study. On average, complaints of pain decreased by approximately $82 \%$. Results were also positive for intensity of pain, which was reduced by $50 \%$ in the first four weeks and by $76 \%$ at the end of the study. There was also an improvement in depression scores of $56 \%$.

According to a study by Likar et al. ${ }^{41}$, there was no difference in the tolerance and safety profiles between patients older and younger than 65 years. Transdermal buprenorphine therefore seems to be a viable option for pain management, but like other opioids, its benefits and risks should be evaluated individually. In addition, it is a high cost drug, hindering its access to the general population ${ }^{41}$.
Morphine

Morphine is a high potency opioid drug which has been used in medicine for more than a century. Again, the present survey did not find studies that evaluated its use specifically among the elderly population. Morphine is widely used in severe pain, surgical and palliative sedation. In recent years there has been a tendency to substitute it with new opioids, and to use it as a parameter of equivalence for such drugs $^{28}$. As with codeine, morphine should be used with caution in patients with renal impairment, requiring adjustment of dosage or replacement with another opioid ${ }^{24}$.

\section{Adjuvant medications}

These are drugs developed for other therapeutic purposes, but which have their analgesic effects verified during use. They are mainly used for the treatment of neuropathic pain.

\section{Antidepressives}

The literature search did not identify studies describing the use of antidepressants in the treatment of chronic pain in the elderly. Tricyclic antidepressants, which act at the presynaptic level by blocking recapture of monoamines, are commonly used in the management of chronic pain related to polyneuropathy and peripheral diabetic neuropathy ${ }^{28}$. However, attention is required when prescribing these drugs, since they can have a large number of side effects including urinary retention, constipation, postural hypotension, sedation, glaucoma and cardiac arrhythmias ${ }^{31}$. They are also related to an increase in the number of falls and the precipitation of delirium, and should therefore be used with care in the elderly ${ }^{28}$. Antidepressant drugs are considered potentially inappropriate for the elderly by the BEERS criteria ${ }^{12}$.

Although the tolerability of selective serotonin reuptake inhibitors is better than that of tricyclics, there are controversies in their use for pain control ${ }^{25}$. The British National Health Institutesuggests duloxetine as an option for pain related to diabetic neuropathy, but does not discuss its use in the elderly ${ }^{28}$. 


\section{Anticonvulsants}

Antiepileptic drugs such as carbamazepine and sodium valproate have already been used in the management of neuropathic pain, and a high incidence of adverse effects, drug interactions and the need for monitoring by laboratory tests have been described. New antiepileptic drugs such as gabapentin and pregabalin have become common in the treatment of pain, as studies have shown their efficacy and safety ${ }^{28,33}$. However, there are no studies evaluating the use of these drugs in the elderly population. In general, it is recommended that use begins at the lowest dose possible, considering renal function, and is then increased according to response and adverse effects ${ }^{25,33}$.

One factor to be considered in the treatment of pain in the elderly relates to the psychosocial aspects of this population. When caring for the elderly, mental health is an essential factor to be evaluated. The rate of depression, which is high in this age group, contributes to the precipitation and perpetuation of chronic pain ${ }^{8,46}$. Degrees of independence and cognitive function should also be considered as they can affect how complaints of pain are manifested, as well as the therapeutic approach to be established and adherence to treatment ${ }^{47}$.

The social condition of the patient is also of fundamental importance. Social determinants impact the prevalence of chronic diseases and their management. Social inequality, low schooling and inequality in access to health services and information are related to a higher prevalence of chronic diseases, their aggravations and poor adherence to treatment ${ }^{47,48}$. Most of the drugs mentioned above, for example, are expensive by Brazilian standards, representing an obstacle to the establishment of adequate treatment.
As it is an integrative review, the study has methodological limitations. The design allows the analysis of different drugs, but more controlled studies are needed for the establishment of better treatment options. The present review found a lack of this type of study, which may be related to the low number of studies among the elderly population. More studies in this population are therefore necessary to contribute to existing evidence and the definition of protocols in the treatment of chronic pain among the elderly.

\section{CONCLUSION}

The management of chronic pain in the elderly is complex due to the comorbidities, polypharmacy, functional status and physiological alterations of this population. Therapeutic planning requires a broad understanding of these variables, as well as the social condition of the patient. Common undesirable effects of various drug classes can be avoided or mitigated with an individualized approach to the patient, especially when several drugs have not been specifically tested for the elderly population. The consequences of inadequately treated chronic pain can worsen comorbidities, decrease the individual's degree of independence, and lead to depression. In general, the geriatric maxim "start low and go slow" should be applied. This involves starting at lower doses which are increased according to tolerability and efficacy, as well as constant patient monitoring. Studies have described the demystification of strong opioids, which are now established as a safe and effective choice when prescribed correctly. In treating chronic pain in elderly patients, the risk-benefit ratio of any drug should be evaluated, based on the recommendations of the current consensus and scientific evidence.

\section{REFERENCES}

1. Organização Mundial da Saúde. Relatório mundial de envelhecimento e saúde. Genebra: OMS; 2015.

2. Celich K, Galon C. Dor crônica em idosos e sua influência nas atividades da vida diária e convivência social. Rev Bras Geriatr Gerontol. 2009;12(3):345-59.
3. Kayser B, Miotto C, Molin VD, Kummer J, Klein $\mathrm{SR}$, Wibelinger LM. Influence of chronic pain on functional capacity of the elderly. Rev Dor. 2014;15(1):48-50.

4. Dellaroza MSG, Pimenta CAM, Lebrão ML, Duarte YA. Associação de dor crônica com uso de serviços de saúde em idosos residentes em São Paulo. Rev Saúde Pública. 2013;47(5):914-22. 
5. Barbosa MH, Bolina AF, Tavares JL, Cordeiro AL, Luiz RB, De Oliveira KF. Sociodemographic and health factors associated with chronic pain in institutionalized elderly. Rev Latinoam Enferm. 2014;22(6):1009-16.

6. Dellaroza M, Pimenta C, Matsuo T. Prevalência e caracterização da dor crônica em idosos não institucionalizados. Cad Saúde Pública. 2007;23(5):1151-60.

7. Treede RD, Rief W, Barke A, Aziz Q, Bennett MI, Benoliel R, et al. A Classification of chronic pain for ICD-11. Pain. 2015;156(6):1003-7.

8. Felix RH, Almeida CB, Cremaschi RC, Coelho FM, Santos FC. Pain-induced depression is related to overestimation of sleep quality in a very elderly population with pain. Arq Neuropsiquiatr. 2017;75(1):25-9.

9. Karp JF, Shega JW, Morone NE, Weiner DK. Advances in understanding the mechanisms and management of persistent pain in older adults. $\mathrm{Br} \mathrm{J}$ Anaesth. 2008;101(1):111-20.

10. American Geriatrics Society. American Geriatrics Society 2015 Updated Beers Criteria for Potentially Inappropriate Medication Use in Older Adults. J Am Geriatr Soc. 2015;63(11):2227-46.

11. Oliveira MG, Amorim WW, Oliveira CRB, Coqueiro HL, Gusmão LC, Passos LC. Consenso brasileiro de medicamentos potencialmente inapropriados para idosos. Geriatr Gerontol Aging. 2017;10(4):168-81.

12. American Geriatrics Society, Panel on Pharmacological Management of Persistent Pain in Older Persons. Pharmacological management of persistent pain in older persons. J Am Geriatr Soc. 2009;57:1331-46.

13. World Health Organization. WHO Guidelines for the pharmacological treatment of persisting pain in adults with medical illnesses [Internet]. Geneva: WHO; 2012 [acesso em 17 out. 2016]. Disponível em: http://www. who.int/medicines/areas/quality_safety/Scoping_ WHO_GLs_PersistPainAdults_webversion.pdf

14. Souza MT, Silva MD, Carvalho R. Revisão integrativa: o que é e como fazer. Einstein. 2010;8(1 Pt 1):102-6.

15. Atkinson TJ, Fudin J, Pandula A, Mirza M. Medication pain management in the elderly: unique and underutilized analgesic treatment options. Clin Ther. 2013;35(11):1669-89.

16. Hirst A, Knight C, Hirst M, Dunlop W, Akehurst R. Tramadol and the risk of fracture in an elderly female population: a cost utility assessment with comparison to transdermal buprenorphine. Eur J Health Econ. 2016;17(2):217-27.
17. Makris UE, Abrams RC, Gurland B, Reid MC. Management of persistent pain in the older patient: a clinical review. JAMA. 2014;312(8):825-36.

18. Manchikanti L, Abdi S, Atluri S, Balog CC, Benyamin RM, Boswell MV, et al. American Society of Interventional Pain Physicians (ASIPP) guidelines for responsible opioid prescribing in chronic non-cancer pain: Part 2--guidance. Pain Physician. 2012;15(3 Suppl):67-116.

19. Kean WF, Rainsford KD, Kean IR. Management of chronic musculoskeletal pain in the elderly: opinions on oral medication use. Inflammopharmacology. 2008;16(2):53-75.

20. Reid MC, Eccleston C, Pillemer K. Management of chronic pain in older adults. BMJ. 2015;350:1-10.

21. Imamura T. Significant efficacy of Tramadol/ Acetaminophen in elderly patients with chronic low back pain uncontrolled by NSAIDs: An Observational Study. Open Orthop J. 2015;9(1):120-5.

22. Wehling M. Non-steroidal anti-inflammatory drug use in chronic pain conditions with special emphasis on the elderly and patients with relevant comorbidities: management and mitigation of risks and adverse effects. Eur J Clin Pharmacol. 2014;70(10):1159-72.

23. Tracy B, Sean Morrison R. Pain management in older adults. Clin Ther. 2013;35(11):1659-68.

24. Malec M, Shega JW. Pain management in the elderly. Med Clin North Am. 2015;99(2):337-50.

25. Kaye AD, Baluch A, Scott JT. Pain management in the elderly population: a review. Ochsner J. 2010;10(3):179-87.

26. Paladini A, Fusco M, Coaccioli S, Skaper SD, Varrassi G. Chronic Pain in the Elderly: the Case for New Therapeutic Strategies. Pain Physician. 2015;18(5):863-76.

27. Gianni W, Ceci M, Bustacchini S, Corsonello A, Abbatecola AM, Brancati AM, et al. Opioids for the treatment of chronic non-cancer pain in older people. Drugs Aging. 2009;26(Suppl 1):63-73.

28. Abdulla A, Adams N, Bone M, Elliott AM, Gaffin J, Jones $\mathrm{D}$, et al. Guidance on the management of pain in older people. Age Ageing. 2013;42 Suppl 1(1):1-57.

29. Gianni W, Madaio AR, Ceci M, Benincasa E, Conati G, Franchi F, et al. Transdermal buprenorphine for the treatment of chronic noncancer pain in the oldest old. J Pain Symptom Manage. 2011;41(4):707-14.

30. Guerriero F. Guidance on opioids prescribing for the management of persistent non-cancer pain in older adults. World J Clin Cases. 2017;5(3):73-81.

31. Barber JB, Gibson SJ. Treatment of chronic nonmalignant pain in the elderly: safety considerations. Drug Saf. 2009;32(6):457-74. 
32. Vellucci R, Mattia C, Celidonio L, Mediati RD. Implications of analgesics use in osteoporotic-related pain treatment: focus on opioids. Clin Cases Miner Bone Metab. 2016;13(2):89-92.

33. Rastogi R, Meek BD. Management of chronic pain in elderly, frail patients: finding a suitable, personalized method of control. Clin Interv Aging. 2013;8:37-46.

34. Kraychete DC, Siqueira JTT, Garcia JBS. Recommendations for the use of opioids in Brazil: Part II. Use in children and the elderly. Rev Dor. 2014;15(1):65-9.

35. Broglio K, Pergolizzi J, Kowalski M, Lynch SY, He E, Wen W. Long-term effectiveness and safety of oncedaily, single-entity, extended-release hydrocodone in patients of $>/=75$ years of age with moderate to severe nonmalignant and nonneuropathic pain. Geriatr Nurs. 2017;38(1):39-47.

36. Vu Bach T, Pan J, Kirstein A, Grief CJ, Grossman D. Use of Methadone as an Adjuvant Medication to lowdose Opioids for neuropathic pain in the frail elderly: A Case Series. J Palliat Med. 2016;19(12):1351-5.

37. Guerriero F, Roberto A, Greco MT, Sgarlata C, Rollone M, Corli O. Long-term efficacy and safety of oxycodone-naloxone prolonged release in geriatric patients with moderate-to-severe chronic noncancer pain: a 52-week open-label extension phase study. Drug Des Devel Ther. 2016;10:1515-23.

38. Lazzari M, Marcassa C, Natoli S, Carpenedo R, Caldarulo C, Silvi MB, et al. Switching to low-dose oral prolonged-release oxycodone/naloxone from WHO-Step I drugs in elderly patients with chronic pain at high risk of early opioid discontinuation. Clin Interv Aging. 2016;11:641-9.

39. Petro E, Ruffini E, Cappuccio M, Guerini V, Belotti G, Fascendini S, et al. Low-dose oral prolongedrelease oxycodone/naloxone for chronic pain in elderly patients with cognitive impairment: an efficacy-tolerability pilot study. Neuropsychiatr Dis Treat. 2016;12:559-69.
40. Guerriero F, Sgarlata C, Marcassa C, Ricevuti G, Rollone M. Efficacy and tolerability of low-dose oral prolonged-release oxycodone/naloxone for chronic nononcological pain in older patients. Clin Interv Aging. 2015;10:1-11.

41. Likar R, Vadlau EM, Breschan C, Kager I, KorakLeiter M, Ziervogel G. Comparable analgesic efficacy of transdermal buprenorphine in patients over and under 65 years of age. Clin J Pain. 2008;24(6):536-43.

42. Vadivelu N, Hines RL. Management of chronic pain in the elderly: focus on transdermal buprenorphine. Clin Interv Aging. 2008;3(3):421-30.

43. Pergolizzi JV, Raffa RB, Marcum Z, Colucci S, Ripa SR. Safety of buprenorphine transdermal system in the management of pain in older adults. Postgrad Med. 2017;129(1):92-101.

44. van Ojik AL, Jansen PA, Brouwers JR, Van Roon EN. Treatment of chronic pain in older people: evidencebased choice of strong-acting opioids. Drugs Aging. 2012;29(8):615-25.

45. Uberall MA, Muller-Schwefe GH. Low-dose 7-day transdermal buprenorphine in daily clinical practice - perceptions of elderly patients with moderate non-malignant chronic pain. Curr Med Res Opin. 2012;28(10):1585-95.

46. Holmes A, Christellis N, Arnold C. Depression and Chronic Pain. Med J Aust. 2010;1(4):17-20.

47. Arruda DCJ, Eta FN, Velten APC, Morelato RL, Oliveira ERA. Fatores associados a não adesão medicamentosa entre idosos de um ambulatório filantrópico do Espírito Santo. Rev Bras Geriatr Gerontol. 2015;18(2):327-37.

48. Schmidt MI, Duncan BB, Azevedo e Silva G, Menezes AM, Monteiro CA, Barreto SM, et al. Chronic noncommunicable diseases in Brazil: burden and current challenges. Lancet. 2011;377(9781):1949-61. 